\title{
Barreras en la ruta de atención de pacientes con cáncer de pulmón
}

Autores: Ana María García Jagua, María Angélica Chacón Manosalva, Félix Eduardo Rangel Miranda, Julián Andrés Osma Hurtado, Fabio Bolivar Grimaldos, Tania Mendoza Herrera, Javier Enrique Fajardo Rivero. Universidad Industrial de Santander, Grupo de investigación MEDITA, Bucaramanga.

\section{INTRODUCCIÓN}

El cáncer de pulmón es una condición altamente letal y en Colombia representa un problema de salud pública. Genera un costo promedio al año siguiente del diagnóstico de US\$7703,7, cuyo monto puede ser reducido al realizar detección temprana articulada a un programa de gestión integral en rutas de atención efectivas.

\section{OBJETIVO}

Reconocer las barreras en la atención de pacientes con cáncer de pulmón, en términos de tiempos, que pudieran afectar la calidad de la prestación del servicio.

\section{METODOLOGÍA}

Estudio observacional, descriptivo, de cohorte retrospectiva. Se incluyeron 247 pacientes con diagnóstico de cáncer de pulmón, atendidos en la unidad de oncología de un hospital de alta complejidad en Bucaramanga, en el periodo comprendido entre enero y diciembre de 2018. Se obtuvieron variables sociodemográficas, clínicas, y administrativas, las cuales fueron evaluadas en Stata 14.

\section{RESULTADOS}

De los datos obtenidos en los 247 pacientes del estudio, pertenecientes en su gran mayoría al régimen de seguridad subsidiado, se encontró que el tiempo promedio de remisión a especialista (medicina interna) desde la consulta de medicina general en atención primaria fue de 66 días. A la realización de tomografía axial computarizada de tórax, de 81 días, desde la presunción diagnóstica y a la consulta especializada de control con imágenes del tórax de 49 días.

\begin{tabular}{|c|c|}
\hline Evento & $\begin{array}{c}\text { Dias para } \\
\text { acceso }\end{array}$ \\
\hline Consulta Medicina Interna & 66 días \\
\hline Realización TAC tórax & 81 días \\
\hline Consulta de control & 49 días \\
\hline
\end{tabular}

CONCLUSIÓN

Se observan unos tiempos de intervención en atención primaria largos posiblemente relacionados a dificultades en la gestión de solicitudes y a la atomización de los pacientes fuera de un programa integral en cáncer o ruta de atención organizada.

1. Ferlay, J, Soerjomataram I, Dikshit R, Eser S, Mathers C, Rebelo $M$ et al. Cancer incidence and mortality worldwide: Sources, methods and major patterns in GLOBOCAN 2012. International Journal of Cancer. 2014;136(5):E359-E386.

2. Pérez N, Murillo R, Hernández G. Costos de la atención médica del cáncer de puimón, la EPOC y el lAM atribuibles al consumo de tabaco en Colombia (proyecto multicéntrico de la OPS). Revista Colombiana de Cancerología. 2007;11(4):241-9.

3. Pardo C, Cendales R. Incidencia, mortalidad y prevalencia de cáncer en Colombia, 2007-2011. Primera edición. Bogotá. D.C. Instituto Nacional de Cancerología, 2015, v.1.p. 148 . 